\title{
SERUM IMMUNOGLOBULIN A (IGA): A CROSSECTIONAL STUDY IN 281 PATIENTS WITH SYSTEMIC LUPUS ERYTHEMATOSUS
}

Anauá Fernanda dos Santos Cavalcante1, ${ }^{1, \star}$ Gustavo F. A. Linzmeyer ${ }^{1}$, Fabiane K. Miyake ${ }^{1}$, Thiago Alberto G. dos Santos ${ }^{1}$, Thelma Larocca Skare ${ }^{1}$

1.Hospital Universitário Evangélico Mackenzie, Curitiba (PR), Brazil.

*Corresponding author: anaua.cavalcante@hotmail.com

\section{BACKGROUND}

Autoimmune diseases linked to IgA deficiency are systemic lupus erythematosus (SLE), rheumatoid arthritis (RA), thyroiditis and celiac disease among others. In the present study, we aimed to know the autoimmune diseases that co-occur in a sample of SLE patients and if this association is higher in those with IgA deficiency.

\section{MATERIAL AND METHODS}

Two hundred eighty-one patients with SLE were studied for IgA levels by nephelometry. Levels equal or under $0.5 \mathrm{~g} / \mathrm{dL}$ were considered as IgA deficiency. Epidemiological and clinical data, including presence of associated autoimmune diseases, were extracted from patient's charts.

\section{RESULTS}

IgA deficiency was found in $6 \%$ of the samples. In $30.2 \%$ of SLE patients there was at least one more autoimmune disease; Hashimoto thyroiditis and Sjögren's syndrome were the most common. No association of the occurrence of associated autoimmune disease with IgA deficiency was found.

\section{CONCLUSIONS}

There is a high prevalence of autoimmune diseases associated with SLE. IgA deficiency does not affect the presence of these associations. 